\title{
Rigid Bronchoscopy in Airway Foreign Bodies: Value of the Clinical and Radiological Signs
}

\author{
Kunjan Acharya ${ }^{1}$ \\ 1 Department of ENT-Head and Neck Surgery, Tribhuvan University \\ Teaching Hospital, Maharajgunj, Kathmandu, Nepal \\ Int Arch Otorhinolaryngol 2016;20:196-201.
}

\begin{abstract}
Address for correspondence Dr. Kunjan Acharya, Department of ENTHead and Neck surgery, Tribhuvan university Teaching Hospital, Maharajgunj Kathmandu Kathmandu 3578, Nepal (e-mail: acharyakunjan@gmail.com; acharyakunjan@hotmail.com).
\end{abstract}

\begin{abstract}
Keywords

- foreign bodies

- bronchoscopy

- airway obstruction

Introduction Foreign body in airway is a common emergency in ENT practice. As we know, Rigid Bronchoscopy is the method of choice for removing it, although at times it leads to specialists performing unnecessary bronchoscopy, exposing patients to hazards of general anesthesia.

Objective The objective of my study is to calculate sensitivity, specificity, positive predictive value, odds ratio from the clinical and radiological signs, comparing with the gold standard, the rigid bronchoscope procedure.

Method This is a prospective analytical study designed at University Teaching Hospital and conducted over a period of 18 months, from March 2011 to August 2012. Data collection was broadly classified into three different categories: (1) Symptomatology, such as presence or absence of choking, cyanosis, and difficulty in breathing; (2) Clinical signs, such as the presence or absence of air entry, crackles, and rhonchi 3. Chest X-ray findings were suggestive of a foreign body.

Results There were a total of 40 rigid bronchoscopies performed under general anesthesia for the diagnosis and therapeutic reasons. Among 40 patients who underwent rigid bronchoscopy, 32 (80\%) were found to have varieties of foreign bodies in their airway while 8 patients (20\%) had negative bronchoscopy. The history of choking is the only clinical symptoms which came out to be statistically Significant $(p=0.043)$ with odds ratio of 5.

Conclusion Rigid bronchoscopy is the gold standard technique for diagnosis and procedure of choice to remove FB from airway. Regardless, it still presents a small chance of negative result, especially when there is no history of aspiration.
\end{abstract}

\section{Introduction}

Airway foreign body (FB) is one of the common emergencies an ENT surgeon must attend to. Its clinical presentation is variable, ranging from a clinically asymptomatic state to dire state of respiratory failure needing urgent attention and intervention. The gold standard for management is rigid bronchoscopy (RB) under general anesthesia.

Rigid bronchoscopy, performed under General Anesthesia (GA), exposes the patient to the risk of GA and the complication of the procedure itself. According to Righini, ${ }^{1}$

received

February 16, 2016

accepted

May 1, 2016

published online

May 30, 2016
DOI http://dx.doi.org/

10.1055/s-0036-1584293. ISSN $1809-9777$. unnecessary rigid bronchoscopy performed under general anesthesia can expose the child to the risk of perioperative procedure complication (8-17\%) like bronchospasm, desaturation and bleeding, or airway edema. Hence, the right decision to perform RB is based on clinical findings and radiological support. My study aims at correlating the clinical presentation and $\mathrm{X}$-ray chest findings with the result of $\mathrm{RB}$ (positive versus negative $\mathrm{RB}$ ).

According to $\mathrm{Hsu}^{2}{ }^{2}$ the usual age group of presentation is between 1-3 years old. However it can occur in older children as well. The crucial decision of performing rigid bronchoscopy

Copyright $(2016$ by Thieme Publicações License terms Ltda, Rio de Janeiro, Brazil

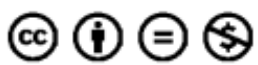


is made on clinical backgrounds. This includes history and clinical findings. It is very important to ask for the history of choking or aspiration from the parents or care-taker. Upon clinical examination, a foreign body in the airway may reveal diminished breath sounds on the affected side or presence of rhonchi or crept. At the same time, two or more findings is possible. Radiological signs can be collapsed lung, radiopaque shadow, or area of consolidation.

The hypothesis of my study is to show the relation of clinical and radiological signs and in cases with presence of FB in the airway. It helps us understand the association of radiological and clinical findings to the results of bronchoscopy to avoid negative bronchoscopy.

\section{Objectives}

The objective of my study is to calculate sensitivity, specificity, positive predictive value, and odds ratio of the clinical and radiological signs and to compare them with the rigid bronchoscopy findings.

\section{Method}

This is a prospective analytical study done over a period of 18 months, from March 2011 to August 2012. All faculties were involved in performing rigid bronchoscopy and foreign body removal. It was done at a tertiary level hospital.

The institutional review board approved the study prior to its undertaking study and the subjects gave their formal consent. The inclusion criteria were all patients with strong clinical suspicion of foreign body in airway with a history of choking, cyanosis, difficulty in breathing, along with the presence of clinical signs, like decreased air entry, cyanosis, or crept. Patients of any age and sex who qualified for the inclusion criteria were included. Before the procedure, the ENT residents examined all patients and noted findings in Performa. After which all patients underwent chest X-ray and at times CT scan of chest whenever indicated. The chest X-Ray was looked for radiological signs, presence of foreign body like collapsed segment, consolidation, trapped air or sometimes the foreign body itself when the foreign body was radio opaque.

Data has been collected broadly into three different categories: (1) Symptomatology, such as the presence or absence of choking, cyanosis, and difficulty in breathing; (2) Clinical signs, such as the presence or absence of air entry, crept, and rhonchi; (3) Radiological signs, such as plain chest X-ray findings.

After proper clinical evaluation and chest X-ray, all patients underwent rigid bronchoscopy under general anesthesia. We used bronchoscopes of the rigid type to perform bronchoscopy. We determined the size of the bronchoscope according to the child's age. After induction of intravenous anesthesia, we performed direct laryngoscopy and inserted the bronchoscope with the help of the laryngoscope in a rotating manner and used a 0 -degree telescope to locate the foreign body. Once identified, we used optical forceps to hold and to remove the foreign body.

However, at times it was not possible to remove FB in the first attempt, and the procedure was repeated after 2-3 days. The decision to continue or to abandon the procedure depended upon the intraoperative bleeding and oxygen

Table 1 Frequency distribution of clinical \& radiological signs

\begin{tabular}{|c|c|c|c|}
\hline & & Present & Absent \\
\hline \multirow[t]{3}{*}{ Symptoms } & H/o choking & $27(67.5 \%)$ & $13(32.5 \%)$ \\
\hline & H/o cyanosis & $8(20 \%)$ & $32(80 \%)$ \\
\hline & $\mathrm{H} / \mathrm{O} \mathrm{SOB}$ & $24(60 \%)$ & $16(40 \%)$ \\
\hline \multirow[t]{10}{*}{ Clinical Signs } & \multirow[t]{4}{*}{ Decreased/absent air entry } & Total 31 (77.5\%) & \multirow[t]{4}{*}{$9(22.5 \%)$} \\
\hline & & Bilateral absent: 2 & \\
\hline & & Unilateral absent: 3 & \\
\hline & & Unilateral decreased: 26 & \\
\hline & \multirow[t]{3}{*}{ Crepitation } & Total $10(25 \%)$ & \multirow[t]{3}{*}{$30(75 \%)$} \\
\hline & & Unilateral crepitation: 8 & \\
\hline & & Bilateral crepitation: 2 & \\
\hline & \multirow[t]{3}{*}{ Rhonchi } & Total 6 (15\%) & \multirow[t]{3}{*}{$34(85 \%)$} \\
\hline & & Unilateral Rhonchi: 5 & \\
\hline & & Bilateral Rhonchi: 1 & \\
\hline \multirow[t]{4}{*}{ Radiological sign } & \multirow[t]{4}{*}{ Chest X-ray } & \multirow[t]{4}{*}{ Normal 19 (47.5\%) } & Abnormal 21(52.5\%) \\
\hline & & & Radiopaque shadow: 8 \\
\hline & & & Consolidation: 3 \\
\hline & & & Collapsed Lung: 10 \\
\hline
\end{tabular}

Abbreviations: $\mathrm{H} / \mathrm{O}$, history of; SOB, shortness of breath. 
Table 2 Analysis between RB findings and clinical manifestation

\begin{tabular}{|c|c|c|c|}
\hline RB Findings & \multicolumn{2}{|c|}{ Clinical Manifestation } & \multirow[t]{2}{*}{$P$ value (Chi square test) } \\
\hline Foreign Body & \multicolumn{2}{|c|}{ History of choking } & \\
\hline & Absent & Present & \multirow{3}{*}{$\begin{array}{l}0.043 \\
\text { Odds ratio: } 5\end{array}$} \\
\hline No FB: 8 & 5 & 3 & \\
\hline \multirow[t]{3}{*}{ FB present: 32} & 8 & 24 & \\
\hline & \multicolumn{2}{|c|}{ Difficulties in breathing } & \\
\hline & Absent & Present & \multirow{3}{*}{$\begin{array}{l}0.439 \\
\text { (using Fisher's Exact Test) }\end{array}$} \\
\hline No FB: 8 & 2 & 6 & \\
\hline \multirow[t]{3}{*}{ FB present: 32} & 14 & 18 & \\
\hline & \multicolumn{2}{|c|}{ History of Cyanosis } & \\
\hline & Absent & Present & \multirow[t]{3}{*}{0.553} \\
\hline No FB: 8 & 7 & 1 & \\
\hline \multirow[t]{3}{*}{ FB present: 32} & 25 & 7 & \\
\hline & \multicolumn{2}{|c|}{ Air entry } & \\
\hline & Normal & Decreased & \\
\hline No FB: 8 & 3 & 5 & 0.256 \\
\hline \multirow[t]{3}{*}{ FB present: 32} & 6 & 26 & \\
\hline & \multicolumn{2}{|c|}{ Crepitation } & \\
\hline & Absent & Present & \\
\hline No FB: 8 & 6 & 2 & 1.00 \\
\hline \multirow[t]{3}{*}{ FB present: 32} & 24 & 8 & \\
\hline & \multicolumn{2}{|c|}{ Rhonchi } & \\
\hline & Absent & Present & \\
\hline No FB: 8 & 7 & 1 & 0.82 \\
\hline \multirow[t]{3}{*}{ FB present: 32} & 27 & 5 & \\
\hline & \multicolumn{2}{|c|}{ Chest X-ray } & \\
\hline & Normal & Abnormal & \\
\hline No FB:8 & 3 & 5 & \multirow[t]{2}{*}{0.52} \\
\hline FB present: 32 & 16 & 16 & \\
\hline
\end{tabular}

Abbreviations: FB, foreign body; RB, rigid bronchoscopies.

saturation. Any amount of bleeding obscuring the surgical procedure and oxygen saturation compromising the anesthetic state of patient led to us to postpone the procedure to the next setting.

After extraction of the foreign body, we repeated bronchoscopy to check for any remaining foreign bodies as well as to examine the tracheobronchial tree for any trauma.

Rigid bronchoscopic findings were correlated with clinical signs and symptoms using SPSS 16 . We calculated sensitivity, specificity positive predictive value. We analyzed the statistical relation of clinical and chest X-ray findings with rigid bronchoscopy.

\section{Results}

There were total of $40 \mathrm{RB}$ performed under general anesthesia for the diagnosis and therapeutic reasons. The age of the patient ranged from 8 months to 13 years. Of the 40 patients, 29 (72.5\%) were men and 11 (27.5\%) were women.

Upon clinical examination, the history of choking was the most common symptom and decreased air entry was the most common finding, as displayed in - Table 1.

Among 40 patients who underwent RB, 32 (80\%) had foreign body in their airway, while 8 patients $(20 \%)$ had negative $\mathrm{RB}$ results.

When the different clinical manifestations were crosstabulated with the rigid bronchoscopy findings, history of choking was the only manifestation, which came out to be statistically significant ( $p=0.043$ ) with odds ratio of 5 . The detailed of cross tabulation between RB findings and clinical manifestation are shown in - Table 2.

Similarly, I used data to calculate sensitivity, specificity, positive and negative predictive value for each of the clinical manifestations, as shown in -Fig. 1. 


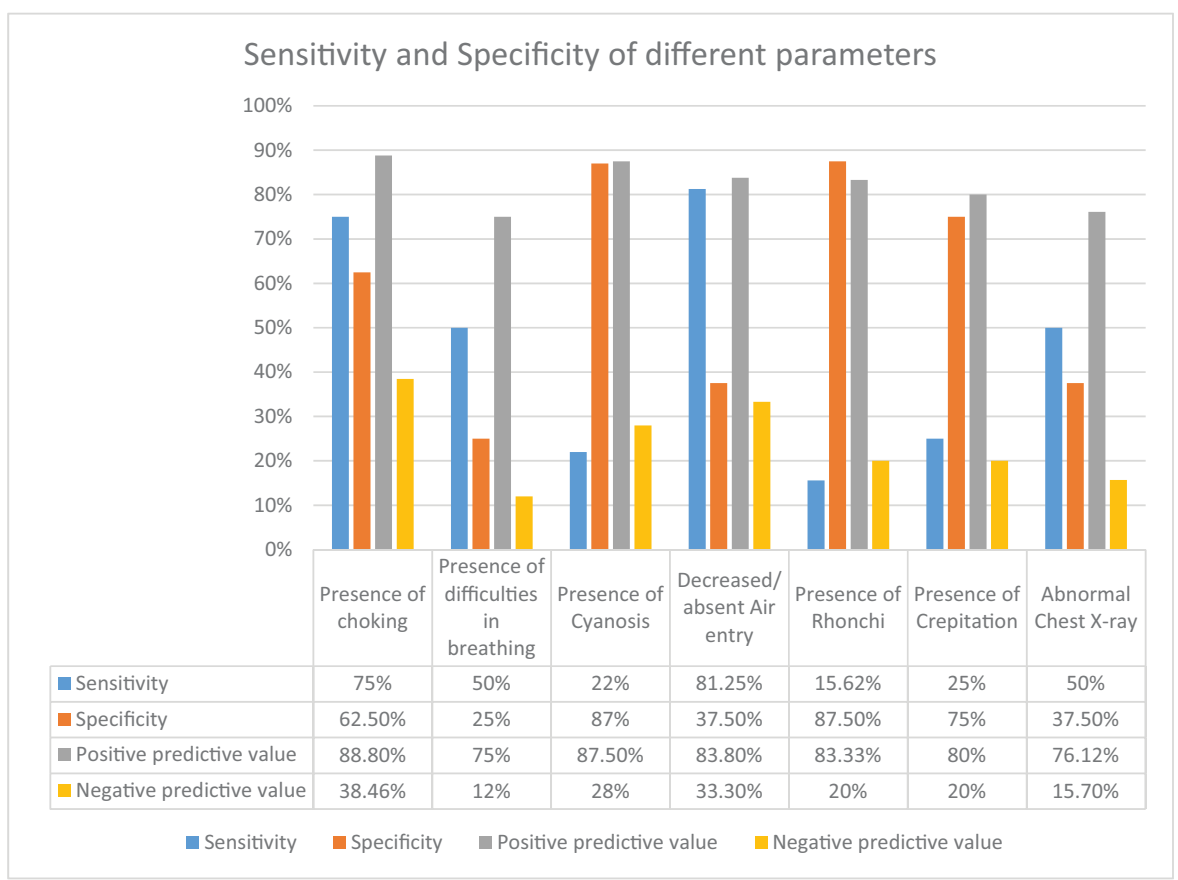

Fig. 1 The chart shows the Sensitivity and Specificity for different clinical variables.

\section{Discussion}

The most common symptom of foreign body aspiration was choking (67.5\%), which was the only statistically significant result in this study. Similarly, decreased air entry was present in $77 \%$ of the patients, but was not significant in our study. However, Righini et al $^{1}$ reveal findings contrary to our study. In their study, the FB aspiration as well as unilateral decreased air entry was statistically significant to the presence of FB in the airway. Similarly, a study done by Gursu Kiyan a $(2009)^{3}$ et al in 192 patients over period of 5 years (2003-2007) showed history of aspiration and decreased air entry both were statistically significant, $\mathrm{p}$ value was $<0.0001$ in both variable.

History of aspiration is important clinical parameter to decide for RB as shown from our study. It is supported by study done by Martinot et al. ${ }^{4}$ He conducted comparative study between Rigid and Flexible Bronchoscopy to find the negative bronchoscopy rate by two different techniques. He adopted a treatment algorithm where he used the child who had history of aspiration were directly channelized to undergo rigid bronchoscopy avoiding the flexible one. This shows asking the history alone is very important and must not be ignored at any cost.

Similarly, sensitivity and specificity of different clinical and radiological signs are displayed in - Fig. 1. However none of the clinical parameters like choking, difficulty in breathing, cyanosis, decreased air entry, rhonchi and crept individually have high sensitivity and specificity together. This might be one of the important factor responsible for predicting the outcome of rigid bronchoscopy. In my study the unilateral decrease in air entry had highest sensitivity of $81 \%$ whereas presence of cyanosis and presence of rhonchi on auscultation had very high specificity of $87 \%$.
The study done by Kiyan et $\mathrm{al}^{3}$ on 192 patients who underwent rigid bronchoscopy, with the presence of wheeze as a symptom, had highest sensitivity at $87.7 \%$, followed by unilateral decreased air entry on auscultation (i.e., 78.3\%). This result slightly varies from this study, as I have not considered wheeze as a symptom during data collection but the sensitivity of unilateral decreased air entry is practically similar. In the same study, the presence of cyanosis had very high specificity, at $98.1 \%$, which was also the highest indicator in our analysis, reaching $87 \%$ specificity. In the Kiyan et $\mathrm{al}^{3}$ study, the presence of productive cough had also very high specificity, at $96.3 \%$, which was not taken into consideration during my study design. However, the presence of rhonchi had highest specificity in my study, but was not the highest in the study by Kiyan et $\mathrm{al}^{3}$ although the value was similar (i.e., 85\%).

The above results signify that there is always a chance of negative bronchoscopy exposing the patients to the hazards of general anesthesia and possible complication of rigid bronchoscopy during the procedure and afterwards. This is because of the inability to identify the single clinical parameter that can almost always predict the presence of foreign in the airway in every case. The rate of negative rigid bronchoscopy was $20 \%$ in my study, which is similar to the other studies done by different authors.

The literature on negative bronchoscopy includes the study done by Oren Cavel et $\mathrm{al}^{5}$ displaying different rates on negative bronchoscopy and its complication, shown in -Table 3. The rate of negative rigid bronchoscopy ranges from $18 \%$ to $43 \%$, with most of them around $20 \%$.

Hence, the alternative modality of investigation is preferable, especially if the clinician does not find a history of aspiration. Also, as suggested by Martinot et $\mathrm{al}^{4}$ in the study 
Table 3 Studies showing different rates of negative RB

\begin{tabular}{|c|c|c|c|c|}
\hline Article & $\begin{array}{l}\text { No. of } \\
\text { Bronchoscopies }\end{array}$ & Negative RB rate & Complications & $\begin{array}{l}\text { Remarks, authors' } \\
\text { comments }\end{array}$ \\
\hline Maddali & 175 & $20 \%$ & $\begin{array}{l}47 \% \text { of cases, mostly minor } \\
\text { anesthetic complications. } \\
\text { Risk factors IV anesthesia } \\
\text { RB time }>30 \text { minute }\end{array}$ & $\begin{array}{l}\text { Retrospective, "to avoid } \\
\text { unwarranted RB, } \\
\text { clinicians should be } \\
\text { aware of the clinical } \\
\text { presentations of FBA" }\end{array}$ \\
\hline Kiyan et $\mathrm{al}^{3}$ & 207 & $26 \%$ & $\begin{array}{l}0.5 \% \text { major } \\
2.9 \% \text { minor }\end{array}$ & $\begin{array}{l}\text { Retro, "with the help of } \\
\text { our low complication } \\
\text { rate, we claim that even } \\
\text { a slight doubt of FBA } \\
\text { using these criteria re- } \\
\text { quires RB to avoid fur- } \\
\text { ther complications of } \\
\text { missed FBA" }\end{array}$ \\
\hline Righini et al ${ }^{1}$ & 54 & $16 \%$ & $\begin{array}{l}4 \% \text { bronchospasm } \\
4 \% \text { subglottic edema }\end{array}$ & $\begin{array}{l}\text { Prospective, propose an } \\
\text { algorithm for choosing } \\
\text { between flexible and RB }\end{array}$ \\
\hline Cohen et $\mathrm{al}^{8}$ & $\begin{array}{l}142 \text { (flexible and RB } \\
\text { under general anesthesia) }\end{array}$ & $57 \%$ & $8.5 \%$ & $\begin{array}{l}\text { Prospective, recom- } \\
\text { mend the use of flexible } \\
\text { or RB depending on } \\
\text { suspicion }\end{array}$ \\
\hline Even et $\mathrm{al}^{9}$ & 98 & $43 \%$ & - & $\begin{array}{l}\text { Prospective, "medical } \\
\text { history is the key for the } \\
\text { diagnosis of FBA. If FBA } \\
\text { is suspected, bronchos- } \\
\text { copy should be } \\
\text { performed" }\end{array}$ \\
\hline${\text { Kadmon et } \mathrm{al}^{10}}^{10}$ & 91 & $\begin{array}{l}47 \%, 14 \% \text { in } \\
\text { Obvious cases }(8 / 59)\end{array}$ & $4 \%$ & $\begin{array}{l}\text { Retrospective, propose } \\
\text { computerized scoring } \\
\text { system to determine } \\
\text { the need for } \\
\text { bronchoscopy }\end{array}$ \\
\hline Ciftci et al ${ }^{11}$ & 663 & $16 \%$ & $\begin{array}{l}5 \%, \text { risk factors - emergency } \\
\text { bronchoscopy, prolonged } \\
\text { procedure, delayed diagno- } \\
\text { sis, type of foreign body } \\
\text { (prayer beads, ball point pen } \\
\text { lid) }\end{array}$ & $\begin{array}{l}\text { Retrospective, no fur- } \\
\text { ther imaging suggested }\end{array}$ \\
\hline Martinot et al ${ }^{4}$ & 28, all "obvious" cases & $18 \%$ & - & $\begin{array}{l}\text { Prospective, RB in ur- } \\
\text { gent or clinically and } \\
\text { radiologically obvious } \\
\text { cases, flexible bron- } \\
\text { choscopy for all the rest }\end{array}$ \\
\hline Hoeve et al $^{12}$ & 115 & $26 \%$ & - & $\begin{array}{l}\text { Retrospective, "if aspi- } \\
\text { ration of FB is consid- } \\
\text { ered, RB is mandatory" }\end{array}$ \\
\hline Rizk, Rassi ${ }^{13}$ & 106 & $23 \%$ & $\begin{array}{l}15 \% \text { required switch to as- } \\
\text { sisted ventilation due to bra- } \\
\text { dycardia and desaturations }\end{array}$ & $\begin{array}{l}\text { Retrospective, } 12 \% \text { of } \\
\text { RB were preceded by } \\
\text { flex due to low } \\
\text { suspension }\end{array}$ \\
\hline
\end{tabular}

Abbreviations: FBA, foreign body aspiration; FB, foreign body; RB, rigid bronchoscopy.

on a patient scheduled to undergo flexible bronchoscopy who had negative history of aspiration before doing rigid bronchoscopy. The flexible bronchoscopy is an alternative tool to detect FB in airway when there is no definite history of aspiration. However, it is difficult to perform in very young children and also has a chance of negative bronchoscopy: $12 \%$ (Righini et al) ${ }^{1}$ and 38\% (Martinot et al). ${ }^{4}$

The other investigating tool in patients with suspicious history of FB in the airway is CT thorax, which for being noninvasive is an alternative to diagnose FB in suspicious 
cases. The study done by Bhat et $\mathrm{al}^{6}$ showed high sensitivity and specificity of CT scan up to 92.3 and $85.5 \%$, respectively, in 20 patients. Similarly, a study done by Bai et $\mathrm{al}^{7}$ in 45 patients had $100 \%$ of sensitivity and specificity in detecting the FB in the airway by using CT scan. Besides the high rate of detection of FB by CT scan, it also locates FB in the airway and gives the number of $\mathrm{FB}$, which definitely helps the surgeon to perform $\mathrm{RB}$ in a planned manner.

\section{Conclusion}

Rigid bronchoscopy remains the gold standard technique of diagnosis and management of airway FB, however it has a small chance of negative result. Similarly, the history of choking is the only clinical parameter which is significantly associated with the presence of FB in airway. Hence, in cases with negative history of choking but with clinical suspicion of FB in the air way, subsequent management should be tailored. Alternative tools for confirming the presence of FB should be utilized, such as like CT scan of thorax or flexible bronchoscopy.

\section{References}

1 Righini CA, Morel N, Karkas A, et al. What is the diagnostic value of flexible bronchoscopy in the initial investigation of children with suspected foreign body aspiration? Int J Pediatr Otorhinolaryngol 2007;71(9):1383-1390

2 Hsu Wc, Sheen Ts, Lin Cd, Tan Ct, Yeh Th, Lee Sy. Clinical experiences of removing foreign bodies in the airway and esophagus with a rigid endoscope: a series of 3217 cases from 1970 to 1996. Otolaryngol Head Neck Surg 2000;122(3):450-454

3 Kiyan G, Gocmen B, Tugtepe H, Karakoc F, Dagli E, Dagli TE. Foreign body aspiration in children: the value of diagnostic criteria. Int J Pediatr Otorhinolaryngol 2009;73(7):963-967

4 Martinot A, Closset $\mathrm{M}$, Marquette $\mathrm{CH}$, et al. Indications for flexible versus rigid bronchoscopy in children with suspected foreign-body aspiration. Am J Respir Crit Care Med 1997;155(5):1676-1679

5 Cavel O, Bergeron M, Garel L, Arcand P, Froehlich P. Questioning the legitimacy of rigid bronchoscopy as a tool for establishing the diagnosis of a bronchial foreign body. Int J Pediatr Otorhinolaryngol 2012;76(2):194-201

6 Bhat KV, Hegde JS, Nagalotimath US, Patil GC. Evaluation of computed tomography virtual bronchoscopy in paediatric tracheobronchial foreign body aspiration. J Laryngol Otol 2010;124(8):875-879

7 Bai W, Zhou X, Gao X, Shao C, Califano JA, Ha PK. Value of chest CT in the diagnosis and management of tracheobronchial foreign bodies. Pediatr Int 2011;53(4):515-518

8 Cohen S, Avital A, Godfrey S, et al. Suspected foreign body inhalation in children: what are the indication for bronchoscopy? J Pediatr 2009;155:276-280

9 Even L, Heno N, Talmon Y, et al. Diagnostic evalution of Foreign body aspiration in Children: a prospective study. J Pediatr Surg 2005;40:1122-1127

10 Kadmon G, Stern Y, Bron E, et al. Computerise scoring system for the diagnosis of foreign body aspiration in children. Ann Otol Rhinol Laryngol 2008;117:839-843

11 Ciftci AO, Bingol-Kologlu M, Senocak ME, et al. Bronchoscopy for evalution of foreign body aspiration in children. J Pediatrl Surg 2003;38:55-57

12 Hoeve LJ, Rombout J, Pot DJ, et al. Foreign body aspiration in children . J Pediatr Surg 2003;38:1170-1176

13 Rizk H, Rassi S. foreign body inhalation in paediatric population : lesson learned from 106 cases. Eur Ann Otorhino Laryngol Head Neck Dis 2011;128(4):169-174 